\title{
Rancangan Meja Penyambung Benang Tenun Dengan Pendekatan Anthopometri dan Biomekanika (Studi Kasus pada PT. PRIMISSIMA)
}

\author{
Suhartono $^{1}$, Fangga Galih Praditya ${ }^{2}$ \\ ${ }^{1,2)}$ Fakultas Sains dan Teknologi, Jurusan Teknik Industri, Universitas Widya Mataram \\ Dalem Mangkubumen KT.III/237 Yogyakarta \\ Email: sharjosaputro@gmail.com, galihradit94@gmail.com
}

\begin{abstract}
ABSTRAK
Penyambungan benang secara manual menggunakan tangan masih dilakukan di PT. Primissima Textil, padahal penenunannya sendiri telah menggunakan mesin modern ITEMA. Akibatnya, sering dijumpai cidera punggung pada Lempeng L5/S1. Tujuan penelitian adalah merancang alat bantu penyambung benang untuk mengurangi gaya kompresi L5/S1. Dimensi alat bantu dihitung menggunakan analisis anthropometri dan dimensi tubuh operator dihitung menggunakan analisis biomekanika dengan mesin ITEMA. Besarnya gaya kompresi punggung dihitung berdasarkan hukum Newton I kesetimbangan $\sum F x=0, \sum F y=0 . \sum M=0$. Hasil penelitian menjumpai nilai factor keamanan batasan NIOSH (National Institute for Occupational Safety and Health) untuk alat bantu yang dihasilkan adalah kurang dari 6500N atau 3,4KN (Maximum Permissible Limit). Spesifikasi dimensi alat bantu adalah panjang sandaran $27,17 \mathrm{~cm}$, tinggi sandaran $99,8 \mathrm{~cm}$, lebar pijakan $43,91 \mathrm{~cm}$, dan lebar alat $100,5 \mathrm{~cm}$. Alat bantu tersebut dapat membentuk gaya kompresi pada Lempeng L5/S1 pada tangan 3,35N, punggung $2,68 \mathrm{~N}$, dan kaki 3,15N, yang aman dan dapat mengurangi gaya tekan L5/S1 pada pekerjaan penyambungan benang.
\end{abstract}

Kata kunci: rancangan, benang, cidera, ergonomic, athopometri dan biomekanika.

\begin{abstract}
The connecting yarn was done manually by hand in PT Primissima Textile, in using of modern ITEMA machine. It affected to lower backbone injury at L5/S1. The aim of study was to planning the connecting yarn device so that can reduce the injury by the compressive strength of the modern ITEMA machine. The device's dimension was described using anthropometric analyses, and the dimension of operator's body using biomechanical analyses in ITEMA Machine. The lower backbone compressive strength was analyzed based on Newton's equilibrium law $\sum F x=\mathbf{0}, \sum F y=\mathbf{0} . \sum M$ =0. The results are safety factor with NIOSH equilibrium (National Institute for Occupational Safety and Health) for the device is determined as <6500N or 3.4KN (maximum safety limit), dimension of the device is back length $27.17 \mathrm{~cm}$, back high $99.8 \mathrm{~cm}$, footing width 43.91 , and device width $100.5 \mathrm{~cm}$. The device forms compressive strength very less than the NIOSH standard, i.e. L5/S1 3.35N for hand, 2.68N for lower backbone, and 3.15N for lags. It will very safe to be applied in the activity of connecting yarn.
\end{abstract}

Keywords: design, yarn, injury, ergonomic, anthropometric and biomechanics.

\section{PENDAHULUAN}

Saat ini, penyambungan benang ketika putus pada pekerjaan produksi pabrik kain PT. Primissima masih dilakukan secara manual dengan tangan, padahal mesin yang dioperasikan telah modern menggunakan mesin ITEMA. PT Primissima terletak di Jl. Magelang km No.15, Sebayu, Triharjo, Kec. Sleman, Kabupaten Sleman, Daerah Istimewa Yogyakarta 55514. Hal itu sering menimbulkan cedera otot punggung bagian bawah, cedera otot tangan dan kaki, terutama pada segmen L5/S1 yang dipicu oleh alat yang tidak ergonomis secara bentuk tubuh. Mesin ITEMA sendiri adalah buatan Italia (Eropa) yang menggunakan standar operator Eropa, dengan postur tubuh yang jauh lebih besar dari postur tubuh orang Asia. Untuk itu diperlukan alat bantu yang memadai untuk mengurangi cedera otot akibat factor kelelahan dan salah urat tersebut. Akibatnya produksi kain tidak optimal, biaya kesehatan meningkat dan perkembangan pabrik stagnan. Tujuan penelitian ini adalah untuk merancang alat bantu yang ergonomis agar operator mesin kain di PT. Primissima tersebut tidak mengalami cedera otot lagi, atau setidaknya mengurangi poteni cedera otot lagi. 
Masalah penelitian ini didekati dengan analisis anthropometri untuk mengetahui dimensi alat bantu dan biomekanika untuk mengetahui dimensi tubuh operator mesin. Dimensi-dimensi tersebut diukur untuk mendapatkan nilai NIOSH (National Institute for Occupational Safety and Health). Nilai NIOSH akan digunakan sebagai dasar dalam rekomendasi dimensi alat bantu untuk mengatasi permasalahan cidera otot.

Whitten dkk (2004) menetapkan factor-faktor yang mempengaruhi kualitas dan kuantitas produksi; yaitu lingkungan dan peralatan kerja. Hal itu dapat didesain dengan mempertimbangkan empat kebutuhan dasar yaitu gerakan, kenyamanan, kompetensi dan pengawasan. Untuk mencapai ke-empatnya, elemen desain dapat ditetapkan berdasarkan konsep antropometri dan ergonomi. Konsep ini mengacu pada desain produk yang sesuai dengan ukuran fisik dan kemampuan pekerja (operator). Menurut (Wignjosoebroto, 2008), antropometri adalah studi yang berkaitan dengan pengukuran dimensi tubuh manusia. Bidang antropometri meliputi berbagai ukuran tubuh manusia seperti berat badan, posisi ketika berdiri, ketika merentangkan tangan, lingkar tubuh, dan panjang tungkai. Data antropometri digunakan untuk berbagai keperluan, seperti perancangan stasiun kerja, fasilitas kerja, dan desain produk agar diperoleh ukuran-ukuran yang sesuai dan layak dengan dimensi anggota tubuh manusia yang akan menggunakannnya (Santosa dkk., 2016; Wicaksana dkk., 2017; Aras dkk., 2019). Analisis antropometri ini bertujuan untuk menjamin tingkat stress pekerja (operator) rendah, efisieni dan aman. Desain peralatan, yang tidak sesuai dengan antropometri operator dapat menimbulkan bahaya bagi pekerja. Esensi dasar dari ergonomi dalam proses perancangan desain adalah sedini mungkin mencoba memikirkan kepentingan operator alat agar bisa terakomodasi dalam setiap kreativitas dan inovasi sebuah 'man made object' (Wignjosoebroto, 2008). Fokus perhatian dari sebuah kajian ergonomis akan mengarah ke upaya pencapaian sebuah perancanganan desain suatu produk yang memenuhi persyaratan 'fitting the task to the man' (Granjean, 1993), sehingga setiap rancangan desain harus selalu memikirkan kepentingan manusia, yakni perihal keselamatan, kesehatan, keamanan dan kenyamanan (Wignjosoebroto, 2008).

\section{METODE PENELITIAN}

Penelitian diawali dengan studi Pustaka, selanjutnya diikuti dengan pengumpulan data meliputi data denyut jantung untuk sebelum $\left(\mathrm{DN}_{0}\right)$ dan saat bekerja $\left(\mathrm{DN}_{1}\right)$, data antropometri untuk tinggi $(\mathrm{H})$ dan berat badan (W), dan data biomekanika. Setelah data terkumpul selanjutnya dilakukan uji kecukupan data. Data dianalisis secara statistic dengan aktivitas sebanyak 30 kali pengukuran. Hasil pengukuran dan uji kecukupan materi tersebut selanjutnya digunakan sebagai dasar dalam menghitung besaran dimensi alat. Alat yang telah didesain selanjutnya dilakukan analisis biomekanika untuk menghitung gaya kompresi pada otot yang berperan, dalam hal ini otot lengan, bahu hingga punggung bagian bawah, dan otot kaki (L5/S1). Selanjutnya dilakukan pengujian alat, jika bernilai $>3,4 \mathrm{kN}$ maka harus dilakukan desain ulang, namun jika bernilai $<3,4 \mathrm{kN}$ maka dinyatakan telah memenuhi standar NIOSH. Alat dapat diaplikasikan, karena dapat mengurangi factor kelelahan.

\section{HASIL DAN PEMBAHASAN}

Dalam perhitungan biomekanika digunakan formula standar yaitu perhitungan gaya kesetimbangan Newton yaitu $\sum F x=0 ; \sum F y=0 ; \sum M A=0$. Perhitungan denyut jantung rata-rata sebelum bekerja / istirahat $\left(\mathrm{DN}_{0}\right)$ (denyut/menit) adalah:

$$
\begin{array}{ll} 
& \bar{X}=\frac{\sum X}{N} \\
\bar{X} & =\text { denyut jantung rata-rata sebelum bekerja / istirahat }\left(\mathrm{DN}_{0}\right) \\
\sum X & =\text { jumlah denyut jantung sebelum bekerja / istirahat }\left(\mathrm{DN}_{0}\right) \\
N & =\text { banyaknya data yang diukur }
\end{array}
$$

Perhitungan denyut jantung rata-rata saat bekerja $\left(\mathrm{DN}_{1}\right)($ denyut/menit) adalah

$$
\begin{array}{ll} 
& \bar{X}=\frac{\sum X}{N} \\
\bar{X} & =\text { denyut jantung rata-rata saat bekerja / istirahat }\left(\mathrm{DN}_{1}\right) \\
\sum_{N} X & =\text { jumlah denyut jantung saat bekerja / istirahat }\left(\mathrm{DN}_{1}\right) \\
& =\text { banyaknya data yang diuku }
\end{array}
$$

Standar deviasi digunakan untuk mengetahui ada tidaknya penyimpangan data dalam pengukuran denyut jantung, dihitung dengan menggunakan rumus : 
$N=$ Banyaknya data yang diukur

$$
\sigma=\left[\frac{N * \sum X^{2}-\left(\sum X\right)^{2}}{N *(N-1)}\right]^{0,5}
$$

$\sigma=$ Standar Deviasi

Dengan menggunakan persamaan (3), standar deviasi denyut jantung saat sebelum bekerja $\left(\mathrm{DN}_{0}\right)$ adalah:

$\sigma=\left[\frac{5 * 34658-(416)^{2}}{5 *(5-1)}\right]^{0,5}=3,42$; sedangkan standar deviasi denyut jantung saat bekerja $\left(\mathrm{DN}_{1}\right)$ adalah: $\sigma=\left[\frac{5 * 60289-(549)^{2}}{5 *(5-1)}\right]^{0,5}=1,48$, data hasil penghitungan disajikan pada Tabel 3 di bawah.

Tahap selanjutnya dilakukan uji keseragaman data melalui penghitungan batas kontrol atas (BKA) dan batas kontrol bawah $(\mathrm{BKB})$ dengan menggunakan rumus :

$$
\begin{aligned}
\qquad \mathrm{BKA}=\bar{X}+k \sigma ; \mathrm{BKB}=\bar{X}-k \sigma \\
\bar{X}=\text { Harga Rata-rata } \\
\sigma \quad=\text { Standar Deviasi } \\
\mathrm{k} \quad=\text { Tingkat Kepercayaan }(95 \%, k=2)
\end{aligned}
$$

Data hasil pengukuran data kesehatan pada beberapa operator mesin ITEMA di PT. Primissima disajikan pada Tabel 1.

Tabel 1. Hasil pengukuran tekanan darah, detak nadi, dan kecepatan rata-rata penyambungan benang pada beberapa pekerja di PT. Primissima (diukur pada bulan Maret 2020)

\begin{tabular}{lcccccccccc}
\hline \multicolumn{1}{c}{ Data } & $\mathrm{a}$ & $\mathrm{b}$ & $\mathrm{c}$ & $\mathrm{d}$ & $\mathrm{e}$ & $\mathrm{f}$ & $\mathrm{g}$ & $\mathrm{h}$ & $\mathrm{i}$ & $\mathrm{j}$ \\
\hline $\begin{array}{l}\text { Tensi Sebelum } \\
\text { kerja }\end{array}$ & $128 / 84$ & $182 / 102$ & $110 / 70$ & $125 / 80$ & $122 / 88$ & $118 / 71$ & $100 / 69$ & $150 / 90$ & $120 / 70$ & $115 / 70$ \\
$\begin{array}{l}\text { Tensi Sesudah } \\
\text { kerja }\end{array}$ & $132 / 84$ & $190 / 120$ & $120 / 78$ & $128 / 88$ & $128 / 90$ & $122 / 88$ & $150 / 72$ & $170 / 110$ & $125 / 81$ & $115 / 70$ \\
$\begin{array}{l}\text { Detak nadi } \\
\text { Sebelum kerja }\end{array}$ & $92 /$ menit & $92 /$ menit & $70 /$ menit & $90 /$ menit & $92 /$ menit & $88 /$ menit & $79 /$ menit & $95 /$ menit & $88 /$ menit & $85 /$ menit \\
$\begin{array}{l}\text { Detak Nadi } \\
\text { Sesudah kerja }\end{array}$ & $87 /$ menit & $90 /$ menit & $68 /$ menit & $88 /$ menit & $88 /$ menit & $80 /$ menit & $75 /$ menit & $90 /$ menit & $87 /$ menit & $82 /$ menit \\
$\begin{array}{l}\text { Kecepatan } \\
\text { rata-rata }\end{array}$ & 31 detik & 20 detik & 25 detik & 20 detik & 27 detik & 21 detik & 25 detik & 27 detik & 30 detik & 28 detik \\
Penyambungan & & & & & & & & & & \\
\hline
\end{tabular}

Hasil analisis pada 10 helai benang lusi yang putus, dengan menggunakan persamaan (4) didapatkan nilai:

1. Rata-rata tensi sebelum kerja $\bar{x}: 127 / 79$

2. Rata-rata tensi sesudah kerja $\bar{x}: 138 / 88$

3. Rata-rata detak nadi sebelum kerja $\bar{x}: 87,1$

4. Rata-rata detak nadi setelah kerja $\bar{x}: 83,5$

5. Rata-rata waktu penyambungan benang : 25,1 detik

Pada pengujian kecukupan data, syarat yang dibutuhkan adalah $\mathrm{N}^{\prime}<\mathrm{N}$, jika dalam pengambilan data tidak sesuai dengan persamaan di atas perlu kiranya manambahkan data kembali dan melakukan uji kecukupan data. Formula uji kecukupan data :

$$
\begin{aligned}
& \qquad N^{\prime}=\left[\frac{k / s \sqrt{N\left(\sum X^{2}\right)}-\left(\sum X\right)^{2}}{\sum X}\right]^{2} \\
& N^{\prime}=\text { Jumlah pengamatan yang seharusnya dilakukan } \\
& k \quad=\text { Tingkat Kepercayaan }(95 \%, k=2) \\
& s \quad=\text { Derajat Ketelitian }(5 \%) \\
& N \quad=\text { Banyak data yang diamati }
\end{aligned}
$$

Dengan menggunakan persamaan (5), nilai kecukupan data dari hasil penelitian adalah: 


$$
\begin{aligned}
\mathrm{N}^{\prime} & =\left[\frac{2 / 0.05 * \sqrt{5 *(34658)-(416)^{2}}}{416}\right]^{2}=\left[\frac{40 * 15,2971}{416}\right]^{2} \\
& =2.16
\end{aligned}
$$

Perhitungan energi kerja dilakukan dengan mengonversi denyut jantung/nadi (beats per minute) ke energi expenditure (Kkal per minute) mengacu pada persamaan berikut (Astuti dkk., 2018):

$$
\begin{aligned}
& \mathrm{Y}=1,80411-0,0229038 \mathrm{X}+4,71733 \cdot 10^{-4} \cdot \mathrm{X}^{2} \\
& \mathrm{Y}=\text { Energi (Kkal/menit) } \\
& \mathrm{X}=\text { Kecepatan Denyut Jantung (denyut/menit) }
\end{aligned}
$$

Jika diketahui denyut jantung rata-rata operator pada saat istirahat $\left(\mathrm{DN}_{0}\right)$ adalah 83,2 , maka energi yang dibutuhkan dihitung menggunakan persamaan (6), adalah:

$$
\begin{aligned}
\mathrm{Y} & =1,80411-0,0229038(83,2)+4,71733.10^{-4}(83,2)^{2} \\
& =1,80411-1,9056+3,2654 \\
\mathrm{Ei} & =3,1639 \mathrm{Kkal} / \text { menit }
\end{aligned}
$$

Denyut jantung rata-rata saat bekerja $\left(\mathrm{DN}_{1}\right)=109,8$

$$
\begin{aligned}
\mathrm{Y} & =1,80411-0,0229038(109,8)+4,71733 \cdot 10^{-4}(109,8)^{2} \\
& =1,80411-2,5148+5,6872 \\
\mathrm{Et} & =4,9765 \mathrm{Kkal} / \mathrm{menit}
\end{aligned}
$$

Setelah kecepatan denyut jantung dikonversikan ke energi, maka pengeluaran energi untuk kerja dapat dihitung dengan menggunakan rumus :

$\mathrm{Ke} \quad=$ Konsumsi energi (kkal)

$$
\mathrm{Ke}=\mathrm{Et}-\mathrm{Ei}
$$

Et $\quad=$ Pengeluaran energi setelah kerja (kkal)

$\mathrm{Ei} \quad=$ Pengeluaran energi saat istorahat $(\mathrm{kkal})$

Pengeluaran energi yang telah dihitung dengan menggunakan persamaan (7) adalah

$$
\begin{aligned}
\mathrm{Et} & =4,9765 \mathrm{Kkal} / \text { menit } \\
\mathrm{Ei} & =3,1639 \mathrm{Kkal} / \text { menit } \\
\mathrm{Ke}=4,9765-3,1639 & =1,8126 \mathrm{Kkal} / \text { menit }
\end{aligned}
$$

Jika energi yang dikeluarkan oleh pekerja dalam kategori ringan atau menengah (moderate) maka perlu dilakukan analisis tambahan yaitu analisis biomekanika. Jika energi yang dikeluarkan dalam kategori berat maka hanya diperlukan analisis energi expenditure (Tabel 2; Woodson dkk., 1992).

Tabel 2. Klasifikasi Beban Kerja (Woodson dkk., 1992)

\begin{tabular}{lccc}
\hline Kategori & $\begin{array}{c}\text { Konsumsi Energi } \\
\text { (Kkal/menit) }\end{array}$ & $\begin{array}{c}\text { Denyut Jantung } \\
\text { (Denyut/menit) }\end{array}$ & $\begin{array}{c}\text { Konsumsi Oksigen } \\
\text { (liter/menit) }\end{array}$ \\
\hline Sangat ringan & $<2,5$ & $<60$ & $<12,5$ \\
Ringan & $2,5-5,0$ & $60-100$ & $0,5-1,0$ \\
Moderate & $5,0-7,5$ & $100-125$ & $1,0-1,5$ \\
Berat & $7,5-10,0$ & $125-150$ & $1,5-2,0$ \\
Sangat Berat & $10,0-12,5$ & $150-175$ & $2,0-2,5$ \\
Berat Ekstrim & $>12,5$ & $>175$ & $>12,5$ \\
\hline
\end{tabular}

Antropometri dihitung menggunakan data analisis hasil pengukuran dimensi tubuh pada 10 operator mesin tenun ITEMA PT Pramissima (Tabel 3). Data hasil analisis antropometri dikorelasikan dengan data hasil pengukuran biomekanika untuk menetapkan dimensi alat, mengacu pada anatomi tubuh manusia; terdiri dari elmen-elmen yang terhubung oleh sendi-sendi dan jaringan otot. Ada dua prinsip dalam analisis biomekanika, yaitu analisis kinematic dan fisik. Data biomekanika mencakup panjang lengan, bahu dan lengan atas, punggung dan pinggang, dan pinggul dan kaki. Karena hasil pengukuran dari ke-10 responden 
sangat bervariasi (Tabel) 3), dimensi alat bantu didasarkan pada data antropometri rata-rata orang Asia (Tabel 4), mengacu Pheasant dkk. (2005). Tinggi dada menentukan panjang dan lebar sandaran (menggunakan presentil ke-95), tinggi tiang penyangga dihitung berdasarkan presentil tinggi pinggang (menggunakan presentil ke-95), lebar pijakan dihitung berdasarkan ukuran kaki operator (menggunakan presentil ke-95), dan lebar alat bantu dihitung berdasarkan precentile ke-5 ukuran lebar bahu. Hasil pengukuran disajikan pada Gambar 1.

Table 3. Data antropometri dari hasil pengukuran 10 orang operator mesin tenun ITEMA di PT. Primissima

\begin{tabular}{|c|c|c|c|c|c|c|c|c|c|c|c|c|c|c|c|}
\hline \multirow[t]{2}{*}{ Data } & \multicolumn{7}{|c|}{ OPERATOR } & & & & \multirow[t]{2}{*}{$\sum$} & \multirow[t]{2}{*}{ SD } & \multirow[t]{2}{*}{ xbar } & \multirow{2}{*}{$\begin{array}{l}\text { BK } \\
\text { A }\end{array}$} & \multirow[t]{2}{*}{ BKB } \\
\hline & 1 & 2 & 3 & 4 & 5 & 6 & 7 & 8 & 9 & 10 & & & & & \\
\hline $\begin{array}{l}\text { Tinggi tubuh berdiri } \\
\text { tegak }\end{array}$ & $\begin{array}{l}17 \\
0\end{array}$ & $\begin{array}{l}16 \\
6\end{array}$ & $\begin{array}{l}16 \\
5\end{array}$ & $\begin{array}{l}16 \\
9\end{array}$ & $\begin{array}{l}16 \\
6\end{array}$ & $\begin{array}{l}16 \\
7\end{array}$ & $\begin{array}{l}16 \\
8\end{array}$ & $\begin{array}{l}17 \\
1\end{array}$ & $\begin{array}{l}16 \\
4\end{array}$ & $\begin{array}{l}16 \\
4\end{array}$ & $\begin{array}{l}167 \\
0\end{array}$ & $\begin{array}{l}2.4 \\
5\end{array}$ & 167 & $\begin{array}{l}168 \\
8\end{array}$ & $\begin{array}{l}165, \\
1\end{array}$ \\
\hline Tinggi pinggang & 93 & 95 & 95 & 98 & 95 & 97 & 96 & 93 & 90 & 90 & 942 & 2.7 & 94.2 & $\begin{array}{l}96,2 \\
3\end{array}$ & $\begin{array}{l}92,1 \\
6\end{array}$ \\
\hline Tinggi bahu duduk & 50 & 50 & 49 & 54 & 51 & 50 & 50 & 55 & 53 & 51 & 513 & 2.0 & 51.3 & $\begin{array}{l}52,8 \\
1\end{array}$ & $\begin{array}{l}49,7 \\
8\end{array}$ \\
\hline Tinggi lutut & 45 & 49 & 46 & 49 & 46 & 50 & 49 & 50 & 49 & 48 & 481 & $\begin{array}{l}1.7 \\
9\end{array}$ & 48.1 & $\begin{array}{l}49,4 \\
5\end{array}$ & $\begin{array}{l}46,7 \\
4\end{array}$ \\
\hline Panjang tangan & 69 & 73 & 63 & 64 & 64 & 49 & 50 & 51 & 49 & 46 & 578 & $\begin{array}{l}9.7 \\
8\end{array}$ & 57.8 & $\begin{array}{l}65,1 \\
8\end{array}$ & $\begin{array}{l}50,4 \\
1\end{array}$ \\
\hline Panjang kaki & 38 & 42 & 38 & 40 & 38 & 42 & 41 & 43 & 40 & 39 & 401 & $\frac{1.8}{5}$ & 40.1 & $\begin{array}{l}41,4 \\
9\end{array}$ & $\begin{array}{l}38,7 \\
0\end{array}$ \\
\hline Lebar bahu & 36 & 36 & 36 & 36 & 35 & 37 & 36 & 37 & 35 & 34 & 358 & $\begin{array}{l}0.9 \\
2\end{array}$ & 35.8 & $\begin{array}{l}36,4 \\
9\end{array}$ & $\begin{array}{l}35,1 \\
0\end{array}$ \\
\hline Tinggi dada & 20 & 20 & 22 & 20 & 20 & 19 & 21 & 25 & 23 & 22 & 212 & $\begin{array}{l}1.8 \\
1\end{array}$ & 21.2 & $\begin{array}{l}21,5 \\
6\end{array}$ & $\begin{array}{l}19,8 \\
3\end{array}$ \\
\hline Berat badan & 48 & 53 & 53 & 50 & 51 & 63 & 62 & 63 & 61 & 59 & 563 & $\begin{array}{l}5.9 \\
0\end{array}$ & $\begin{array}{l}56.2 \\
5\end{array}$ & $\begin{array}{l}60,7 \\
0\end{array}$ & $\begin{array}{l}51,7 \\
9\end{array}$ \\
\hline Usia & 43 & 24 & 42 & 28 & 30 & 29 & 35 & 40 & 38 & 39 & 348 & $\begin{array}{l}6.6 \\
1 \\
\end{array}$ & 34.8 & & \\
\hline
\end{tabular}

Tabel 4. Data model anthropometrik orang Indonesia menggunakan model Asia $\left(\mathrm{H}^{\mathrm{a}}=\right.$ Total tinggi badan, tegap dan berdiri $(\mathrm{cm}), \mathrm{W}^{\mathrm{b}}=$ Total berat badan (Newton); Pheasant dkk., 2005)

\begin{tabular}{lcc}
\hline \multicolumn{1}{c}{$\begin{array}{c}\text { Segmen tubuh } \\
\text { (digunakan dalam contoh kerja) }\end{array}$} & $\begin{array}{c}\text { Segmen } \\
\text { Panjang frasksi } \mathrm{H}^{\mathrm{a}}\end{array}$ & $\begin{array}{c}\text { Segmen } \\
\text { Berat fraksi W }\end{array}$ \\
\hline Kepala dan leher & 17 & 0.08 \\
Lengan bawah & 20 & 0.02 \\
Tangan & 40 & 0.05 \\
Kepala,leher,dan kedua lengan & - & 0.18 \\
Thorax dan perut & 30 & 0,36 \\
Panggul & - & 0,16 \\
Kaki dan betis & 29 & 0,05 \\
Paha & 24 & 0,10 \\
Kaki & 53 & 0,15 \\
Kepala,leher,kedua tangan,thorak,perut,dan & - & 0,60 \\
panggul pertiga perdelapan & & 0,25 \\
Satu kaki dan panggul lima perdelapan & - & \\
\hline
\end{tabular}
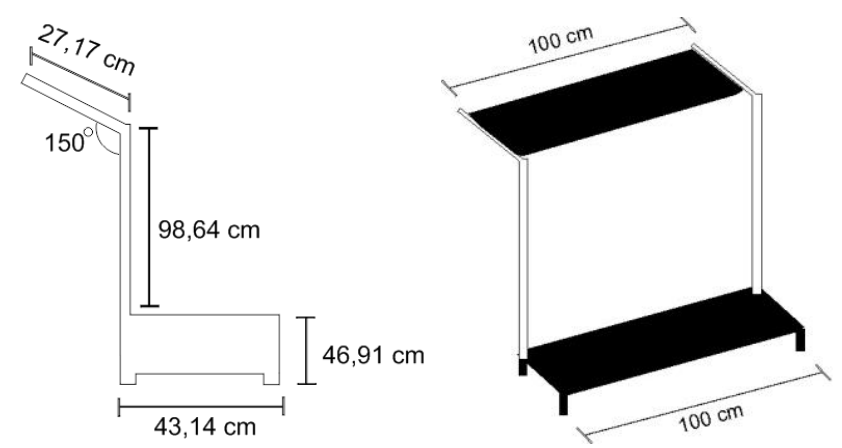

Gambar 1. Desain alat bantu operator tenun ITEMA tampak samping (kiri) dan pijakannya tampak depan (kanan) 
Pengujian alat bantu telah dilakukan, pengujian penggunaan alat bantu ini dengan prosedur (1) berdiri tegak di atas bangku pijakan dan memposisikan badan secara aman dan nyaman; (2) punggung membungkuk $30^{\circ}$ mengarah ke benang yang putus; dada menopang di atas papan bangku penyangga, agar beban badan tubuh disangga oleh papan penyangga alat bantu; (3) melakukan gerakan-gerakan relaksasi pada jam istirahat sehingga tubuh terasa lebih segar, waktu beristirahat adalah 5 menit setelah bekerja 30 menit. Posisi tubuh free body diagram yang tak menggunakan alat bantu dibandingkan dengan yang menggunakan alat bantu: (1) untuk beban lengan dapat dilihat pada Gambar 2, (2) untuk beban punggung pada pusat pinggang dan kaki dilihat pada Gambar 3.

Perhitungan biomekanika didasarkan pada analisis free body diagram saat penyambungan benang, didapatkan posisi tubuh melalui 4 dimensi pemodelan per segmen tubuh saat penyambungan benang. Data antropometri untuk tinggi tubuh 1,63m dan berat badan 52,68 kg memiliki gaya kompresi 516,264 N. Satuan yang digunakan adalah untuk jarak (meter), berat (newton), dan sudut (derajat).
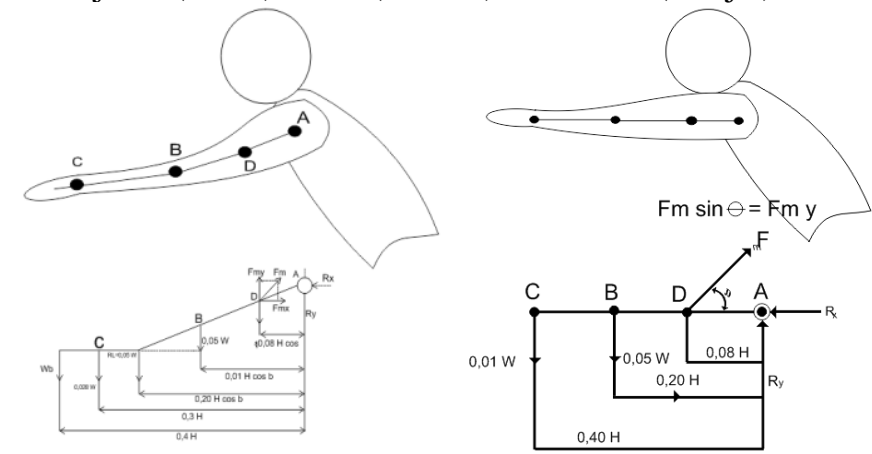

Gambar 2. Diagram gerak bebas tangan dan bahu berdasarkan hasil penghitungan biomekanik (Tabel 3-4) yang tidak menggunakan alat bantu (kiri) dan menggunakan alat bantu (kiri).
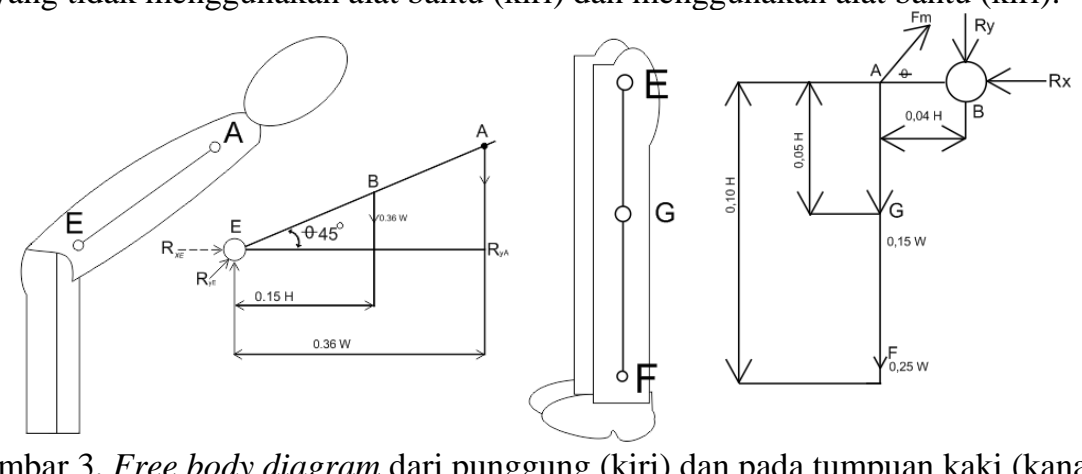

Gambar 3. Free body diagram dari punggung (kiri) dan pada tumpuan kaki (kanan)

Besarnya beban yang ditahan saat bekerja dihitung berdasarkan gaya otot yang dilepaskan oleh masing-masing segmen searah garis vertical, beban pada kaki yang bertumpu adalah $\sum \mathrm{Fy}=31,54 \mathrm{~kg}$ (Zen, 2014). Besarnya gaya kompresif pada L5/S1 yang direkomendasikan oleh NIOS (1981) berdasarkan gaya tekanan pada punggung di daerah Lumbar 5 Sacruml (L5/S1) adalah 3400 Newton; diperkirakan ada 99\% pria dan $75 \%$ wanita mampu mengangkat beban itu. Batasan gaya angkat maksimum yang direkomendasikan NIOSH (1981) berdasarkan gaya tekanan pada punggung di daerah L5/S1 adalah 6400 Newton, namun hanya $25 \%$ pria dan $1 \%$ wanita yang mampu melewatinya (Nurmianto, 1996; Zen dkk, 2016). Hasil dari perhitungan gaya tekanan pada punggung di daerah L5/S1 terhadap operator tenun mesin ITEMA setelah menggunakan alat bantu untuk beban komperesi rata-rata berat, sedang dan ringan di daerah L5/S1 adalah 2,87 Newton pada segmen lengan, 26,83 Newton pada segmen punggung dan 31,54 Newton pada segmen kaki. Nilai gaya tekan pada operator tenun mesin ITEMA setelah menggunakan alat bantu ternyata berada dibawah The Maximum Premissible Limit, jadi kondisi pengangkatan ini sangat aman dan nyaman (Sukanto, 2016). Dari hasil simulasi perubahan sudut lengan, bahu dan punggung, perbaikan alat mesin ITEMA dilakukan dengan merubah-rubah landasan kaki, yang akan merubah sudut bahu terhadap bidang vertical saat penyambungan (Gambar 4; Zen, 2014). Perubahan signifikan pada alat bantu operator tenun mesin ITEMA adalah pada dimensi tinggi pijakan dan sandaran dada yang semula belum sesuai ukuran presentil ergonomi standar operator Indonesia. Dengan adanya perbaikan pada ketinggian alat ini akan mengurangi resiko cidera punggung akibat tubuh terlalu membungkuk dan kurang jangkauan tangan dengan frame kamran mesin ITEMA. Di samping itu juga akan mengurangi beban pada kaki yang bertumpu; dengan efisiensi $21,81 \%$ dan kapasitas produksi setelah penggunaan alat bantu meningkat sebesar 78,6, dan selisih waktu penyambungan 3detik yang semula 25,1 detik (Tabel 5). 


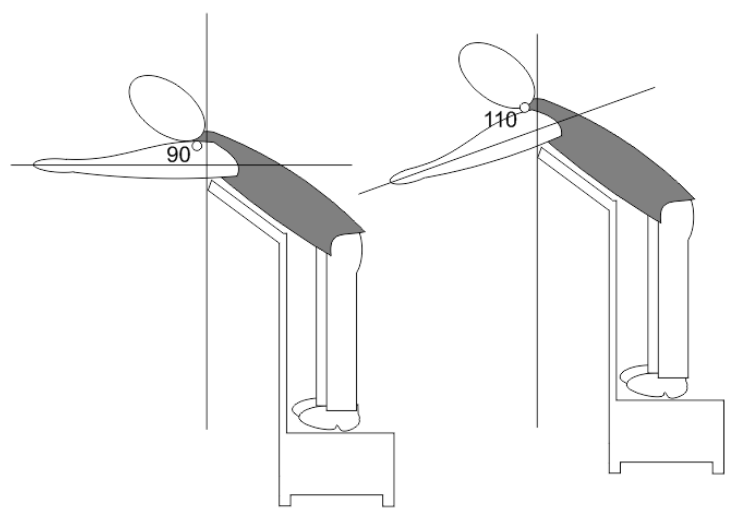

Gambar 4. Skema penggunaan alat bantu operator tenun, dengan merubah tinggi-rendahnya pijakan kaki yang selanjutnya juga turut merubah dimensi sandaran dada

Tabel 5 perbandingan pengukuran kerja sebelum dan sesudah mengunakan alat.

\begin{tabular}{llcccc}
\hline No & $\begin{array}{c}\text { Data rata-rata pengukuran } \\
\text { Kerja }\end{array}$ & Satuan & $\begin{array}{c}\text { Sebelum } \\
\text { Mengunakan } \\
\text { alat }\end{array}$ & $\begin{array}{c}\text { Sesudah } \\
\text { Mengunakan } \\
\text { alat }\end{array}$ & Selisih \\
\hline 1 & Tensi sebelum bekerja & $\mathrm{mm} / \mathrm{Hg}$ & $127 / 79$ & $129 / 79$ & $2 / 0$ \\
2 & Tensi sesudah bekerja & $\mathrm{mm} / \mathrm{Hg}$ & $138 / 88$ & $137 / 88$ & $1 / 0$ \\
3 & Detak nadi sebelum bekerja & per menit & 83,5 & 83,4 & 0,1 \\
4 & Detak nadi setelah bekerja & per menit & 87,1 & 89,9 & 2,8 \\
5 & Waktu penyambungan & detik & 25,1 & 22,1 & 3,0 \\
6 & Kapasitas produksi & detik & 197,4 & 276,0 & 78,6 \\
7 & Efisiensi produksi & $\%$ & 56,83 & 78,64 & 21,81 \\
\hline
\end{tabular}

Pada analisis antropometri mesin ITEMA diperoleh dimensi alat bantu untuk perbaikan pada segmen kerja penyambungan benang yang putus dengan dimensi alat adalah ditentukan panjang sandaran $27,17 \mathrm{~cm}$, tinggi sandaran $98,64 \mathrm{~cm}$, lebar pijakan $43,91 \mathrm{~cm}$, dan lebar alat 100,5 cm. Alat ini utamanya mengatur tinggi pijakan kaki dan meja sandaran lengan-dada, yang dapat merubah sudut lengan terhadap bidang vertical hingga membentuk sudut $90-110^{\circ}$. Dari analisis biomekanika didapatkan ukuran beban kerja dengan kompresi pada tubuh saat melakukan penyambungan benang adalah 33,54 $\mathrm{N}$ pada segmen lengan, 26,83 $\mathrm{N}$ pada segmen punggung, dan 31,54 $\mathrm{N}$ pada segmen kaki. Besarnya gaya kompresi yang dihasilkan saat penyambungan benang dengan menggunakan alat bantu yang baru dikategorikan aman untuk L5/S1. Alat bantu itu mampu meningkatkan produktivitas mesin ITEMA dengan nilai efisiensi meningkat sebesar 21,8\%.

Analisis antropometri dan biomekanika sangat bermanfaat dalam desain teknis dan penyesuaian teknis berbagai peralatan di bidang industry. Selain untuk modifikasi mesin ITEMA dalam penyambungan benang yang putus, Purwaningsih dkk. (2017) melakukan perancangan stasiun kerja menggunakan software Jack 8.2, dengan mengevaluasi desain teknis alat kerja, yang juga didasarkan pada postur kerja dengan menggunakan analisis biomekanik. Hasilnya metode ini cukup membantu mengurangi cedera otot, sebagaimana yang dilakukan pada proses evaluasi desain mesin ITEMA tersebut. Peneliti yang lain, yaitu Riski (2019) melakukan evaluasi desain ergometer dayung atlet dayung di Aceh, dengan mendasarkannya pada hasil analisis biomekanika. Hasil evaluasi tersebut mampu meningkatkan kecepatan dayung dan motorboat, sedangkan factor cidera otot pun dapat diminimalisasi hingga 28,8\%. Fatmasari (2018) juga melakukan evaluasi pengemudi Catamaran Motorboat; dan cedera otot pun dapat dihindari melalui perhitungan nilai momen inersia berdasarkan biomekanika pada segmen tubuh head, neck, and trunk dan mendapatkan selisih nilai yang cukup besar apabila dibandingkan dengan segmen tubuh yang lain. Hal itu juga mempengaruhi kestabilan pengemudi saat mengemudi Catamaran Motorboat. Begitu juga dengan Samosir (2015) yang juga menggunakan analisis biomekanika dan antropometri dalam mengevaluasi tata letak dan K3 pada Pidoa Sepuh Collection. Jadi, analisis antropometri dan biomekanika dapat diaplikasikan untuk meningkatkan produktivitas di bidang industry, olahraga, dan transportasi. Metode ini tentunya dilandasi dengan evaluasi kinerja alat dan operatornya sebelum dan sesudah aplikasi. Intinya, metode ini dapat membantu dalam menyelesaikan permasalahan desain teknis peralatan dan kegiatan yang belum / tidak sesuai dengan postur tubuh operatornya, dengan akurasi yang signifikan. Untuk pekerjaan yang menggunakan mesin ITEMA yang pada awalnya belum sesusai dengan postur tubuh operator Asia, hasil analisis ini mampu meningkatkan performa kerja sebesar $21,8 \%$, sehingga produktivitas kerja meningkat dan waktu operasional yang lebih pendek. 


\section{SIMPULAN}

Analisis antropometri telah sangat membantu dalam melakukan evaluasi kinerja peralatan di sector industry dan di berbagai sector lain. Melalui analisis antropometri dan biomekanika tersebut, diketahui dimensi peralatan yang seharusnya sesuai dengan postur operator yang telah dimiliki oleh perusahaan tersebut. Metode ini juga sekaligus dapat digunakan sebagai landasan modifikasi peralatan, sehingga tidak perlu dilakukan pembelian peralatan lagi. Dengan demikian pengadaan peralatan dapat ditekan, dan produktivitas dapat ditingkatkan tanpa harus menambah jumlah atau mengganti operator. Begitu juga, biayabiaya perawatan kesehatan pun dapat ditekan, karena factor kelelahan dan cidera otot dapat ditekan.

\section{UCAPAN TERIMA KASIH}

Ucapan Terima Kasih ditujukan kepada PT. Primissima Yogyakarta yang telah memberikan kesempatan melakukan penelitian. Ucapan terimakasih juga ditujukan kepada Lembaga Penelitian dan Pengabdian kepada Masyarakat Universitas Widya Mataram Yogyakarta yang telah mendanai penelitian. Ucapan terimakasih juga ditujukan kepada semua pihak yang terkait.

\section{DAFTAR PUSTAKA}

Agustina, A., \& Maulana, I. (2013). Rancang Ulang Kursi Taman dengan Evaluasi Ergonomi-Antropometri dan Biomekanik.

Aras, A. F., Rahmatika, D., \& Putra, E. (2019). Perancangan meja laptop portable yang ergonomis untuk penyandang cerebral palsy dengan pendekatan antropometri. Jurnal Inovator, 2(1), 16-19.

Arifki, M. P. (2018). Analisis Manual Material Handling Operator Stasiun Pressing dengan Metode Biomekanika pada PT. XYZ.

Astuti, B., Mahmudah, S. N., Marwoto, P., Ariyanto, D., \& Wibowo, E. (2018). Oxygen Effect in Annealing Process of Aluminium Doped Zinc Oxide Films. EDUCATUM Journal of Science, Mathematics and Technology, 5(2), 33-39.Grandjean, E., 1993, Fitting the Task to the Man, 4th ed., Taylor and Francis Inc., London

Fatmasari, A.R. (2018). Analisis Postur Kerja Pada Pengemudi Catamaran Motorboat Dengan Pendekatan Biomekanika (Doctoral dissertation, Universitas Brawijaya).

Nurmianto, E. (1996). Ergonomi konsep dasar dan aplikasinya. Surabaya: Guna Widya.

Pheasant, S., \& Haslegrave, C. M. (2005). Bodyspace: Anthropometry, ergonomics and the design of work. CRC press.

Rizki, M.N. (2019). Analisis Pengaruh Antropometri Dan Biomekanik Atlet Aceh Pada Desain Ergometer Dayung. Etd Unsyiah.

Samosir, E.H. (2015). Analisis dan Usulan Perancangan Fasilitas Fisik Berdasarkan Biomekanika, Antropometri, Tata Letak dan K3 (Studi Kasus di Pidoa Sepuh Collection Bandung) (Doctoral dissertation, Universitas Kristen Maranatha).

Sanjaya, K. T., Wirawan, N. H., \& Adenan, B. (2018). Analisis postur kerja manual material handling menggunakan biomekanika dan NIOSH. JATI UNIK: Jurnal Ilmiah Teknik dan Manajemen Industri, 1(2), 70-80.

Santoso, A., Anna, B., \& Purbasari, A. (2016). Perancangan Ulang Kursi Antropometri Untuk Memenuhi Standar Pengukuran. Profisiensi, 2(2).

Sukanta, S. (2016). Perancangan Ulang Proses Pengisian Cream Biskuit Berdasarkan Konsep Biomekanika Dan Antropometri Di Pt. Ceres Meiji Indotama. Barometer, 1(1), 21-24.

Wicaksana, B. I. A., \& Nugroho, Y. J. D. (2017). Perancangan Stasiun Kerja Penyoletan Dengan Metode Antropometri Dan Rapid Upper Limb Assesment (RULA).

Wignjosoebroto, S. (2008), Ergonomi Studi Gerak dan Waktu, edisi ke-2, Guna Widya, Surabaya.

Woodson, W. E., Tillman, B., \& Tillman, P. (1992). Human factors design handbook: information and guidelines for the design of systems, facilities, equipment, and products for human use.

Zen, Z. H., Anggraini, D. A., \& Ananda, P. R. (2016). Analisis Aspek Ergonomi Jembatan Penyeberangan Di Kota Pekanbaru Dan Usulan Perancangan Jembatan Yang Ergonomis. 1th Celscitech-UMRI 2016, 1, 95-101.

Zen, Z.H. (2014). Perancangan Alat Material Handling dengan Menggunakan Pendekatan Biomekanika dan Postur Kerja pada Bagian Pengepakan Pupuk di CV. Bukitraya Laendrys Bukittinggi. 